Review Article

\title{
Formaldehyde Use and Alternative Biobased Binders for Particleboard Formulation: A Review
}

\author{
Stephen Warui Kariuki ${ }^{D}$, Jackson Wachira ${ }^{D}$, Millien Kawira, and Genson Murithi \\ Department of Physical Sciences, University of Embu, P.O. Box 6-60100, Embu, Kenya \\ Correspondence should be addressed to Stephen Warui Kariuki; stephowarui@yahoo.com
}

Received 30 June 2019; Revised 1 September 2019; Accepted 19 September 2019; Published 13 October 2019

Guest Editor: Zhichao Jin

Copyright (c) 2019 Stephen Warui Kariuki et al. This is an open access article distributed under the Creative Commons Attribution License, which permits unrestricted use, distribution, and reproduction in any medium, provided the original work is properly cited.

\begin{abstract}
Formaldehyde-based resins are conventionally used as a binder in formulation of particleboard. Epidemiologic studies have shown that formaldehyde is carcinogenic. Efforts to reduce the health hazard effects of the fomaldehyde-based resin in the particleboard formulation have included use of scavengers for formaldehydes and use of an alternative binder. Use of scavengers for the formaldehyde increases the cost and maintenance of particleboard formulation. There is no proof that scavengers eliminate the emission of formaldehyde from particleboard. Use of biobased binders in particleboard formulation provides an alternative for eliminating use of the formaldehyde-based resin. However, the alternative is hindered by challenges, which include limitations of physical and mechanical properties. The challenge has continuously been acted upon through research. The paper presents an overview of the use of starch as an alternative binder. Improvement over time of the starch and limitations thereof requires to be addressed. Use of the modified starch has shown increased particleboard performance. Mechanical strength, such as modulus of rupture, modulus of elasticity, and internal bonding in particleboards, however, remains to be a challenge.
\end{abstract}

\section{Introduction}

1.1. Formaldehyde-Based Resins and Particleboard Formulation. Formaldehyde is used in industries for the synthesis of resins and adhesives used during formulation of particleboard [1]. Phenol formaldehyde (PF) resins are used as adhesive for fixing together panels of exterior-grade plywood, the flakes of oriented strandboard panels, and particleboard [2]. Phenol formaldehyde resins provide high standards of physical and mechanical properties, which involve high strength and resistant to moisture. This prevents delamination and gives excellent temperature stability. This is due to the more flexible nature of phenolic resins [3]. However, high cost of PF is due to fluctuations in cost of phenols and undergoes hydrolysis to emit formaldehydes. Investigation aimed at use of cheaper and formaldehyde-free products as substitute of phenol-formaldehyde, based on not only environmental but also economic grounds. Lignin has comparatively low price and high phenolic moieties along with environmental considerations render it as a suitable substitute for phenols in the manufacture of $\operatorname{PF}[4,5]$.

Urea formaldehyde (UF) resin is widely used as adhesives in the particleboard industry. UF is cheaper compared to PF. There are two major limitations of wood composite boards based on UF binders: first, high emission of formaldehyde during both production, and second, subsequent exploitaion of the boards [6]. Particleboard formulated with urea formaldehyde shown pronounced thickness swelling to water, and hence, they are unsuitable for outdoor use [7]. Measures used to reduce formaldehyde emissions involve decrease of the formaldehyde/ urea molar ratio [8]. Unfortunately, the decrease in formaldehyde/urea ratio has resulted in deterioration of physical and mechanical properties of particleboard at the same time.

1.2. Formaldehyde Emission and Formaldehyde Scavangers. The other method used to reduce formaldehyde emission is by use of chemical additives called formaldehyde scavangers. 
The most commonly used scavangers are compounds containing amine such as urea, ammonia, melamine, and dicyandiamide [9]. Melamine reacts with formaldehyde to form methylolamine as shown in equation (1) [10]:

$$
\mathrm{C}_{3} \mathrm{H}_{6} \mathrm{~N}_{6}+\mathrm{CH}_{2} \mathrm{O} \longrightarrow \mathrm{C}_{4} \mathrm{H}_{8} \mathrm{~N}_{6} \mathrm{O}
$$

Dicyandiamide reacts with two moles of formaldehyde as illustrated in equation (2) to form methyloldicyanamides [11]:

$$
\mathrm{C}_{2} \mathrm{H}_{4} \mathrm{~N}_{4}+2 \mathrm{CH}_{2} \mathrm{O} \longrightarrow \mathrm{C}_{4} \mathrm{H}_{6} \mathrm{~N}_{4} \mathrm{O}
$$

Urea reacts with formaldehyde to form monomethylolurea as shown in equation (3) [12, 13]. Urea formaldehyde resin is used in formulation of particleboard as a binder, other than a scavanger.

$$
\mathrm{CO}\left(\mathrm{NH}_{2}\right)_{2}+\mathrm{CH}_{2} \mathrm{O} \longrightarrow \mathrm{C}_{2} \mathrm{H}_{6} \mathrm{~N}_{2} \mathrm{O}_{2}
$$

Sodium metabisulphite $\left(\mathrm{Na}_{2} \mathrm{~S}_{2} \mathrm{O}_{5}\right)$ is a scavenger used in particleboards produced with urea formaldehyde and melamine formaldehyde resins. Sodium metabisulphite reacts with water to form sodium hydrogen sulfite, as shown in equation (4).

$$
\mathrm{Na}_{2} \mathrm{~S}_{2} \mathrm{O}_{5}+\mathrm{H}_{2} \mathrm{O} \longrightarrow 2 \mathrm{NaHSO}_{3}
$$

Sodium metabisulphite reacts with formaldehyde as a scavenger to form a bisulfite adduct [14] as shown in equation (5):

$$
\mathrm{HCHO}+\mathrm{NaHSO}_{3} \longrightarrow \mathrm{HOCH}_{2} \mathrm{SO}_{3} \mathrm{Na}
$$

Sodium hydrogen sulfite also reacts with sodium hydroxide to form sodium sulfite, as shown in equation (6):

$$
\mathrm{NaHSO}_{3}+\mathrm{NaOH} \longrightarrow \mathrm{H}_{2} \mathrm{O}+\mathrm{Na}_{2} \mathrm{SO}_{3}
$$

Sodium sulfite scavenger formaldehyde in the presence of water to form bisulfite adduct, as in equation (7) [14].

$$
\mathrm{HCHO}+\mathrm{Na}_{2} \mathrm{SO}_{3}+\mathrm{H}_{2} \mathrm{O} \longrightarrow \mathrm{NaOH}+\mathrm{NaSO}_{3} \mathrm{CH}_{2} \mathrm{OH}
$$

Ammonia is a good scavenger for the emitted formaldehyde [15]. Green tea catechin as a formaldehyde scavenger reduced formaldehyde from plywood manufactured with formaldehyde-based resin. Green tea extract reduced formaldehyde emissions from plywood [16]. Proanthocyanidic was found to protect kidney tissue against formaldehyde [17]. Tannin was mixed with low molecular phenolformaldehyde resin in manufacture of plywood. It was used to scavenge against emitted formaldehyde [18].

Prolonged human exposure of formaldehyde lead to chronic toxicity and cancer $[12,19]$. Formaldehyde can cause nasopharyngeal cancer [20]. Lu et al. [21] reported on genotoxic and cytotoxic modes of action for the carcinogenesis of inhaled formaldehyde in respiratory nasal epithelium [21]. An increased incidence of myeloid leukemia has been reported.

Increased exposure of formaldehyde to workers in a funeral homes resulted in mortality from myeloid leukemia [22] and lymphohematopoietic malignancies [23-25]. The most consistent pattern was death as a result of myeloid leukemis
[26]. A study of 11,039 textile workers produced a certain relationship between the duration of formaldehyde exposure and leukemia-related deaths [27]. The exposure assessment based on 594 workers produced the mean exposure levels between 0.09 and $0.20 \mathrm{ppm}$, and the levels were relatively constant with no peaks or intermittent exposures. Leukemia had the highest standardized mortality ratio (SMR) with majority of occurrences from garment factory. The epidemiological literature on formaldehyde and leukemia is extensive. Many studies have shown a correlation between formaldehyde and cancer-related complications [26].

\subsection{Use of Starch and Starch Derivatives as Substitutes for} Particleboard Formulation. Adhesive technology is moving towards replacements of formaldehyde-based adhesives to use of biobased resources [28-30]. Various types of starch modification on its crystalline nature include chemical treatments such as oxidation using hypochlorite [31] and air [32], esterification [33], and cationization [34, 35]. Physical modification of starch includes mechanical activation [36], microwave $[37,38]$, ultrasonic degradation $[39,40]$, heatmoisture treatment [41], and enzymatic treatment [42-44]. The modified starch has been utilized in particleboard formulation [45-48].

Selamat et al. [46] compared physical and mechanical properties of particleboard formulated from rubberwood with urea formaldehydes and native starch, separately as binders. The native starch was extracted from oil palm trunk. Particleboard bonded with formaldehyde showed thickness swelling of $11.17 \%$ and water absorption of $82.08 \%$, when compared to the native starch with thickness swelling of $82.08 \%$ and water absorption of $174.52 \%$ [46]. This shows that formaldehyde-based resin is more than twice better than the carboxymethyl starch, although the main drawback is emission of formaldehyde. Formaldehyde has been found to have carcinogenic properties [21, 49-51]. High water absorption of particleboard formulated with the carboxymethyl starch may be attributed to the presence of hydroxyl groups. Hydroxyl groups form hydrogen bonding with water. This increases water absorption and thickness swelling, thus affecting mechanical properties of the particleboards. Methylene diphenyl diisocyanate (MDI) were small and had better mechanical and chemical bonding ability [52]. Improvement in chemical bonding results in improvement in mechanical properties of the particleboard formulated.

Natural starch is in the disorganized metastable state and as such is easily dispersed in warm water [53]. Carboxymethylation therefore is a chemical modification method that is vital and versatile for transforming starch. Transformation of starch involves provision of water soluble polymers and intermediate of valuable functional attributes [54]. Carboxymethylation of starch (CMS) involves partial substitution of hydroxyl group (-OH) with ether group (-O$\mathrm{CH}_{2} \mathrm{COOH}$ ). Starch reacts with monochloroacetic acid to produce carboxymethyl in the presence of sodium hydroxide in three different steps. Step one involves reaction of starch with starch, as shown in equation (8): 


$$
\mathrm{ROH}+\mathrm{NaOH} \longrightarrow \mathrm{RONa}+\mathrm{H}_{2} \mathrm{O}
$$

Step two involves the reaction between sodium salt formed with monochloroacetic acid to form sodium monochloroacetate (SMCA) as shown in equation (9):

$$
\mathrm{RONa}+\mathrm{ClCH}_{2} \mathrm{COONa} \longrightarrow \mathrm{ROCH}_{2} \mathrm{COONa}+\mathrm{NaCl}
$$

Alternatively, SMCA reacts with sodium hydroxide to form sodium glycolate:

$$
\mathrm{NaOH}+\mathrm{ClCH}_{2} \mathrm{COONa} \longrightarrow \mathrm{HOCH}_{2} \mathrm{COONa}+\mathrm{NaCl}
$$

Carboxylmethylation therefore improves the rheological property of the native starch that improves particleboard characteristics [54].

Starch in water undergoes limited reversible swelling, but the integrity of the crystal structure is such that it does not dissolve [55]. Starch gelatinization at low temperatures can be induced by addition of aqueous alkali [56]. Sodium hydroxide reacts with hydroxyl groups of starch thus improving the thickness swelling and water absorption of the native starch by $8 \%$ and $22 \%$, respectively. This is attributed to reduction of hydroxyl groups that were reacted with sodium hydroxide. Another reason could be as a result of reaction between carboxylic group in monochloroacetic acid and hydroxyl groups in starch through esterification process. Particleboard bound with urea formaldehyde had the highest modulus of rupture (MOR) values for medium density of $9.63 \mathrm{~N} / \mathrm{mm}^{2}$, while those bound by the native starch gave the lowest of $3.38 \mathrm{~N} / \mathrm{mm}^{2}$. Same trend was found in modulus of elasticity and internal bonding with $3369.12 \mathrm{~N} / \mathrm{mm}^{2}, 2068.95 \mathrm{~N} / \mathrm{mm}^{2}$ and $1.98 \mathrm{~N} / \mathrm{mm}^{2}, 0.96 \mathrm{~N} / \mathrm{mm}^{2}$, respectively [46]. Improved mechanical strength from the native starch to carboxymethyl starch is attributed to the cross-linking of the composite material with highly branched carboxymethyl, leading to formation of stronger covalent bonds than hydrogen bonding found in the native starch. Carboxymethyl starch treatment improved the MOR, thus attaining the minimum Japanese Industrial Standard [46]. MOR is still very low compared to particleboard formulated from urea formaldehyde. There is no interaction between the functional groups of the lignocellulose material and the starch, which leaves a major deficit in reinforcement of the bond between the components of the particleboard. This presents a challenge that requires consideration. Treatment with sodium hydroxide and temperature reduces the sizes of starch making them disperse more within the lignocellulose matrix.

Despite the growing interest in bioplastics, the use of starch-based plastic is still limited due to its brittleness and moisture sensitivity. Addition of polyvinyl alcohol (PVA) reduces the brittleness of the bioplastic [57], and latex increases water resistance [58]. Shi and Tang [47] used polyvinyl alcohol solution with styrene-butadiene (SBR) latex and polymeric methyl diphenyl diioscyanate to modify corn starch. Particleboard formulated showed MOR range from $13.26 \mathrm{~N} / \mathrm{mm}^{2}$ to $16.54 \mathrm{~N} / \mathrm{mm}^{2}$, MOE range from $1508 \mathrm{~N} / \mathrm{mm}^{2}$ to $1768 \mathrm{~N} / \mathrm{mm}^{2}$, and IB range from $0.17 \mathrm{~N} /$ $\mathrm{mm}^{2}$ to $0.32 \mathrm{~N} / \mathrm{mm}^{2}$ [47]. Starch-based adhesives gave the particleboard better prepressing property and sizing uniformity. Pan et al. [59] used polymeric methylene diphenyl diisocyanate to modify rice bran for making an adhesive for making particleboard. Average MOE for particleboard formulated was $2545 \mathrm{~N} / \mathrm{mm}^{2}$, MOR, $21 \mathrm{~N} / \mathrm{mm}^{2}$, and IB of $0.35 \mathrm{~N} / \mathrm{mm}^{2}$ [59]. The study showed that the rice bran adhesive produced can be used to replace a portion of the synthetic adhesive pMDI currently used for the fabrication of rice straw particleboard. Addition of PVA, latex, and SBR will improve moisture resistance, water absorption, and thickness swelling which in turn reduces mechanical properties.

Xu et al. [60] used butyl acrylate (BA) as a comonomer in synthesizing the corn starch-based wood adhesive. The bonding performance was close to that of commercial polivinyl alcohol solution. This cassava-based wood adhesive (SWA) improved in stability more than the corn starchbased wood adhesive. Improved stability was attributed by its low minimum film forming temperature (MFFT) and glass transition temperature $\left(T_{\mathrm{g}}\right)$ of the cassava starch [60]. Zhu and Zhuo [61] used butyl acryrate to modify the corn starch used for encapsulating carborxylic-containing compounds through graft copolymerization. The encapsulated organic materials showed low swellability, large encapsulating capacity, and low solubility in water [61]. Low swellability property is crucial in formulation of particleboards. Liu and Su [62] used butyl acrylate to modify potato starch through grafting via surface-initiated atom transfer radical polymerization [62]. Graft modification provides a significant route to alter physical and mechanical properties of biobased adhesives [63].

Starch contains many hydroxyl groups, which make it extremely polar leading to low interaction with nonpolar materials [64]. Starch-based adhesives wet the polar surfaces of cellulose, penetrate crevices and pores, and, thus, form strong bonds. Imam et al. [65] cross-linked corn starch with polyvinyl alcohol (PVOH) using hexamethoxy methylmelamine (HMMM) to bond lignocellulose materials together in an acidic medium. Under this condition, methoxy groups from HMMM reacted with the hydroxyl group from starch in the presence of PVOH to form ether bond [65], as in Scheme 1.

Ether bonds are covalent bonds which are stronger than hydrogen bonding in starch. The binder in formulated particleboard remained intact showing superior bond strength establishment. The boards fractured during mechanical testing. This is attributed to use of an acid media during particleboard formulation. The use of an acid media limits activation of functional groups in lignocellulose materials. Particleboard made from rice straw and the polyvinyl starch-based adhesive gave the following results: MOR, IB, and TS of up to $31 \mathrm{~N} / \mathrm{mm}^{2}, 0.49 \mathrm{~N} / \mathrm{mm}^{2}$, and $20 \%$, respectively [65]. Use of urea formaldehyde-based resin as a binder gave MOE, IB, and TS of up to $22.19 \mathrm{~N} / \mathrm{mm}^{2}, 0.5 \mathrm{~N} /$ $\mathrm{mm}^{2}$, and $75 \%$ [66]. Researchers worked with different particle sizes and found that the starch-based adhesive gave comparatively better physical and mechanical properties. Properties of polyvinyl alcohol-based resin were greatly influenced by the interaction between the adhesive and 

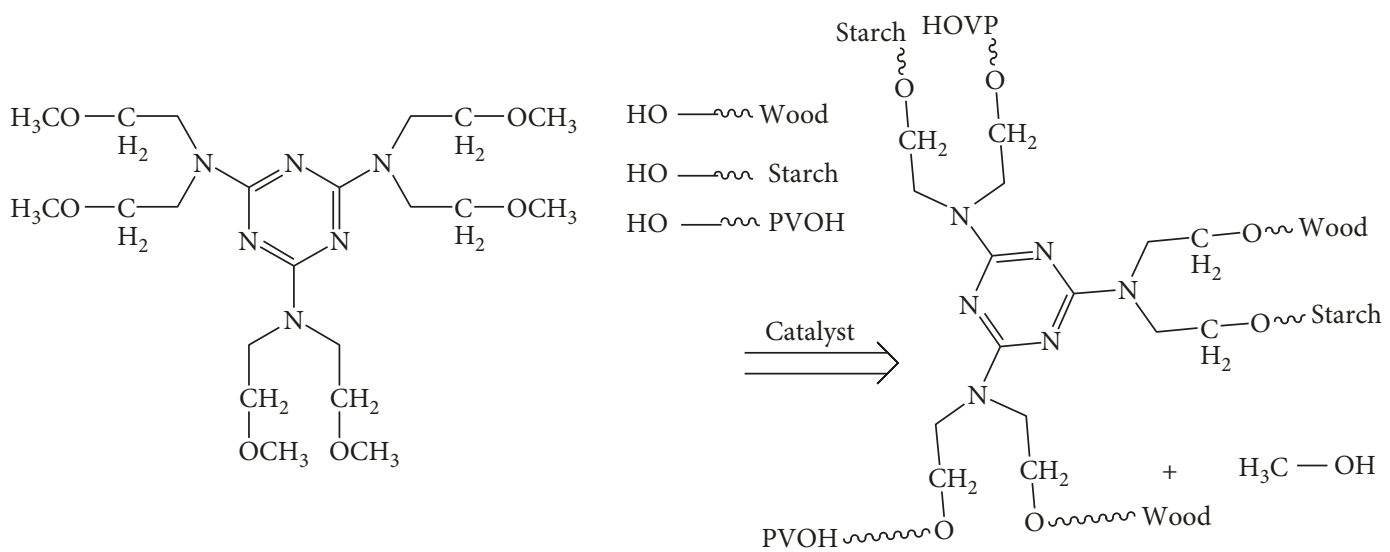

Scheme 1: Schematic chemical crosslinking reaction [65].

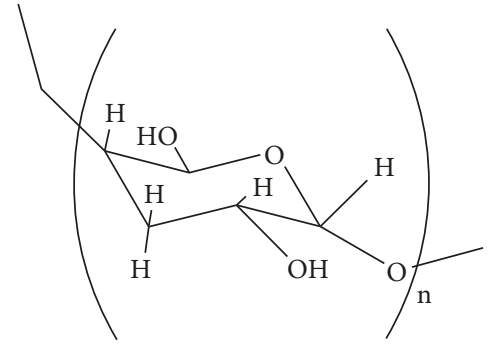

Starch

Glutaraldehyde

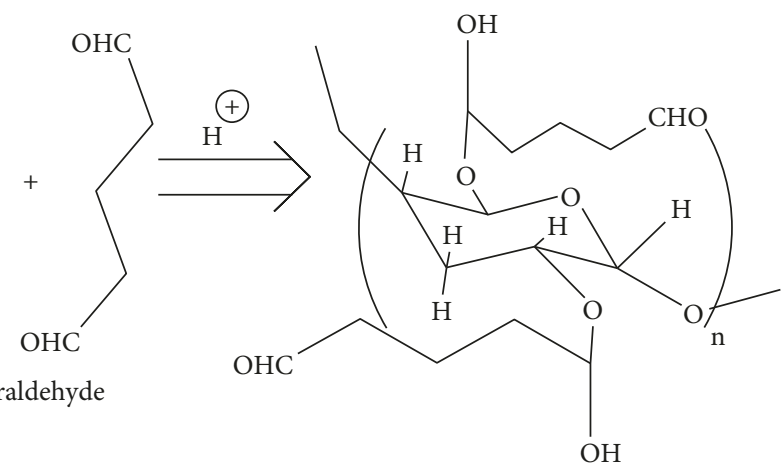

Scheme 2: Modified starch by glutaraldehyde.

lignocellulose material. These properties are still below expectations and can be boosted by use of an alkali, which activates functional groups in lignocellulose materials [67].

Akinyemi et al. [68] used glutaraldehyde to degrade the cassava starch in the presence of acidic medium. Hydroxyl groups in starch molecules were replaced by glutaraldehyde as indicated in Scheme 2.

The modified starch was used to bind wood chips in formulation of sawdust particleboard. Particleboard formulated using this modified starch gave the following results: MOE and MOR of $3232 \mathrm{~N} / \mathrm{mm}^{2}$, and $35.7 \mathrm{~N} / \mathrm{mm}^{2}$, respectively. Comparatively, melamine-formaldehyde (MF), was also used by Cui et al. [69] to obtain MOE and MOR of $2701 \mathrm{~N} / \mathrm{mm}^{2}$ and $14.21 \mathrm{~N} / \mathrm{mm}^{2}$, respectively [68]. MF undergoes hydrolysis leading to produce formaldehyde. Starch modified with glutaraldehyde gave better mechanical strength than their formaldehyde counterpart. Glutaraldehyde is harmful, and this has necessitated the use of sodium bisulfate as a scavenger to neutralize its effect [70]:

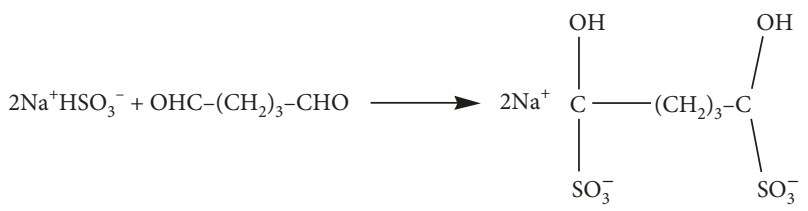

Starch reacts with polyurethane polymer via terminal hydroxyl group in starch through grafting [71], as shown in Scheme 3.

Polar hydroxyl groups are replaced with the hydrophobic aromatic urethane functional group [72]. Polyurethane has been used to modify castor oil starch used in formulation of particleboard made from sugarcane bagasse. The board had WA, TS, MOE, MOR, and IB of up to $20.1 \%$, $20 \%, \quad 22.6 \mathrm{~N} / \mathrm{mm}^{2}, \quad 2850 \mathrm{~N} / \mathrm{mm}^{2}$, and $1.18 \mathrm{~N} / \mathrm{mm}^{2}$, respectively [73]. Urea formaldehyde and melamine formaldehyde resin binders for sugarcane bagasse produced WA, TS, MOR, MOE, and IB of $64.87 \%$ and $32.52 \%, 24.71 \%$ and $12.66 \%, 757.8 \mathrm{~N} / \mathrm{mm}^{2}$ and $1053.28 \mathrm{~N} / \mathrm{mm}^{2}, 3.66 \mathrm{~N} / \mathrm{mm}^{2}$ and $5.53 \mathrm{~N} / \mathrm{mm}^{2}$, and $0.2 \mathrm{~N} / \mathrm{mm}^{2}$ and $0.45 \mathrm{~N} / \mathrm{mm}^{2}$, respectively [74]. Formaldehyde-based resin produces formaldehyde which is a carcinogen. Although modified starch resin produced higher physical and mechanical properties compared to its formaldehyde-based resin, its properties are still very low. Mechanical properties of particleboard made using starch-based adhesive modified polyurethane improved by crosslinking with lignocellulose material.

Starches modified with octenyl succinic anhydride (OSA) have been used in a range of industrial applications, particularly as a food additive. OSA is hydrophobic and also has steric effects. Starch reacts with OSA to form starch octenyl succinate as shown in Scheme 4. 


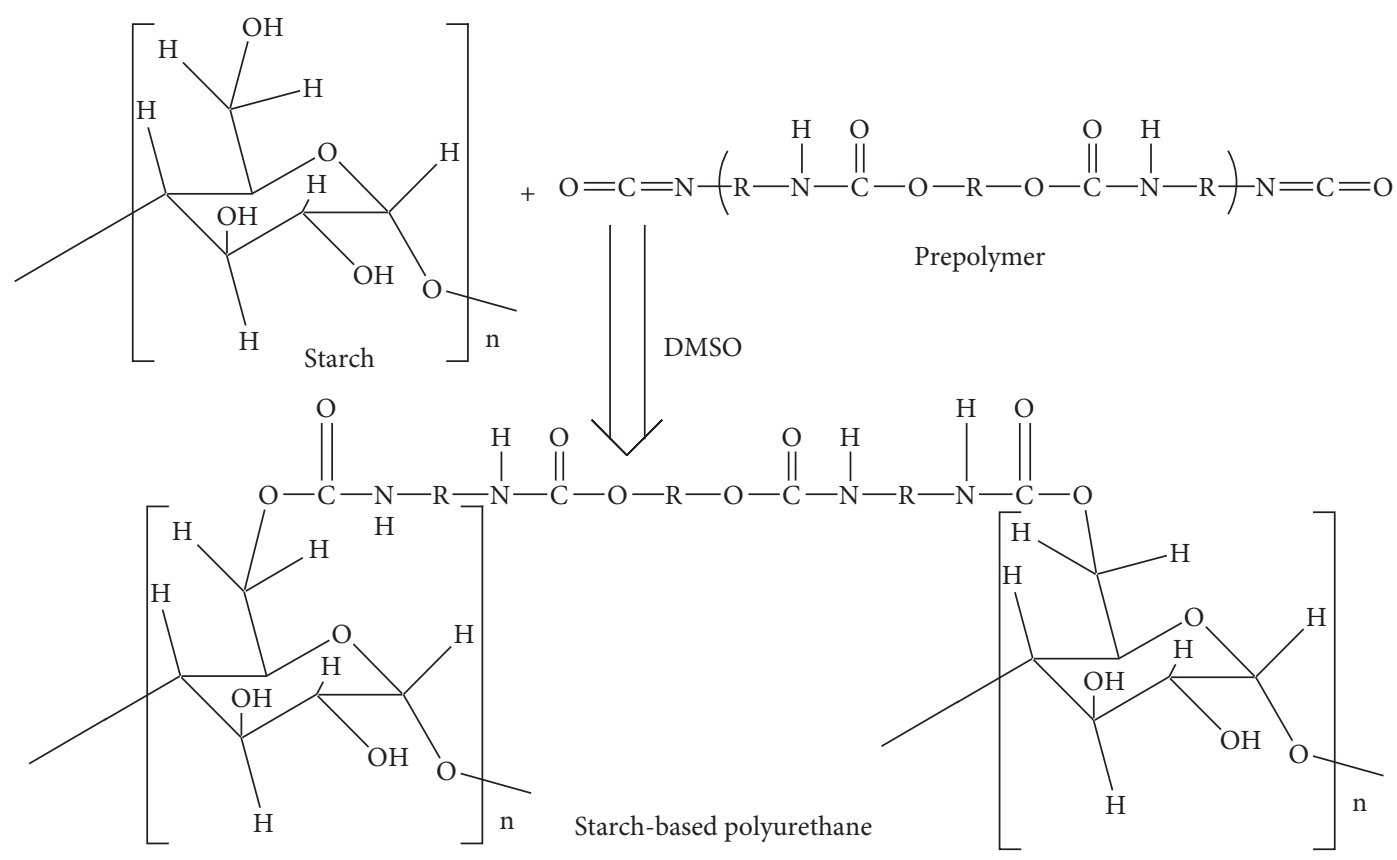

Scheme 3: Preparation of starch-based polyurethane [70].
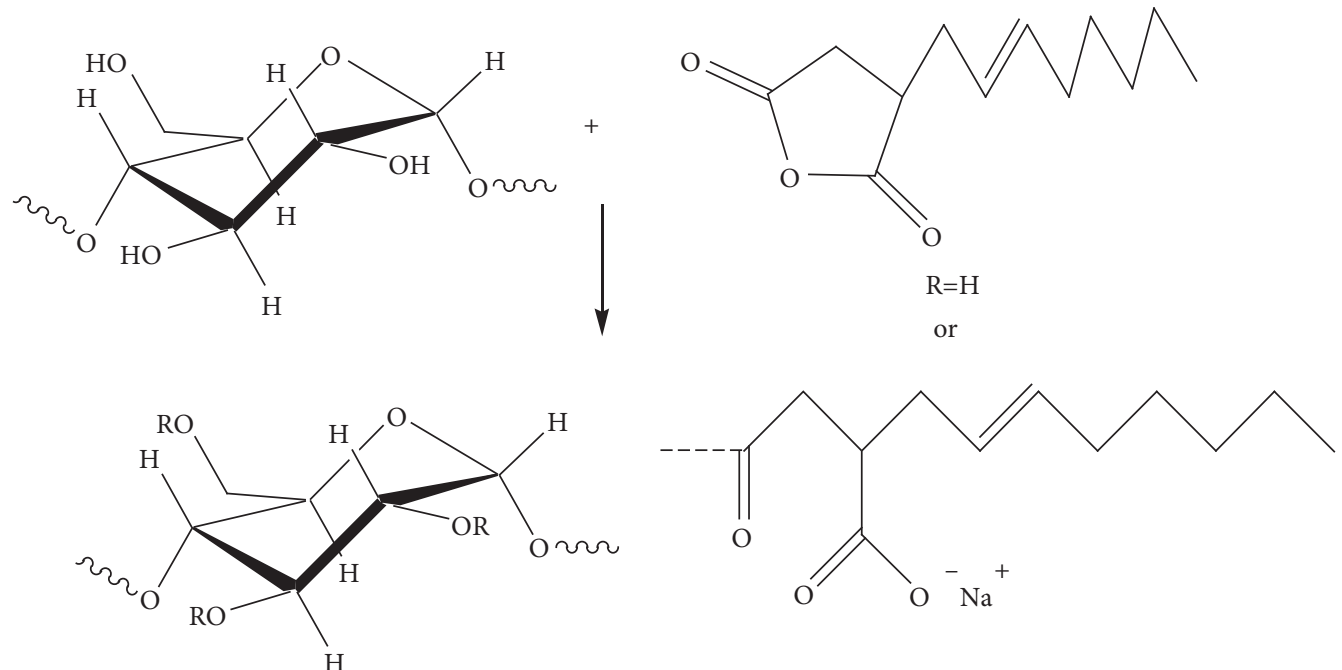

Scheme 4: Reaction showing starch modified with octenyl succinic anhydride (OSA).

Sweedman et al. [75] modified indica rice, maize, waxy maize, and potato with octenyl succinic anhydride (OSA) between the temperatures of 30 to $40^{\circ} \mathrm{C}$. Due to hydrophobic and steric contributions of OSA and highly branched macromolecular starch structure, modified starch display useful stabilizing, encapsulating, interfacial, thermal, nutritional, and rheological properties [75]. Altuna et al. [76] modified starch with octenyl succinic anhydride to yield a hydrocolloid with amphiphilic properties, the octenyl succinylated starch. The octenyl succinylated starch finds wide application in the food industry mainly as emulsifier, encapsulating agent, and fat replacer [76]. Research investigating the reaction between OSA and modified waxy maize starch showed that OSA reacts with maltodextrine better than the native starch. This indicates incorporation of OSA into hydrated granules [77].

Succinic anhydride reacts with starch by refluxing with pyridin or by gelatinization of starch in aqueous pyridine. This is followed by a reaction with succinic anhydride in pyridine. Pyridine has a dual function in the reaction, activates starch, which makes it nucleophillic, and reacts with succinic anhydride to form succinyl pyridinium intermediate. The intermediate reacts with starch generating starch succinate and pyridine as shown in Scheme 5 [78].

Mehboob et al. [79] used succinic anhydride to modify the native sorghum starch and acid-thinned starch. Succinylation of starch introduces succinyl groups that have hydrophilic character to starch [79]. This group weakens 


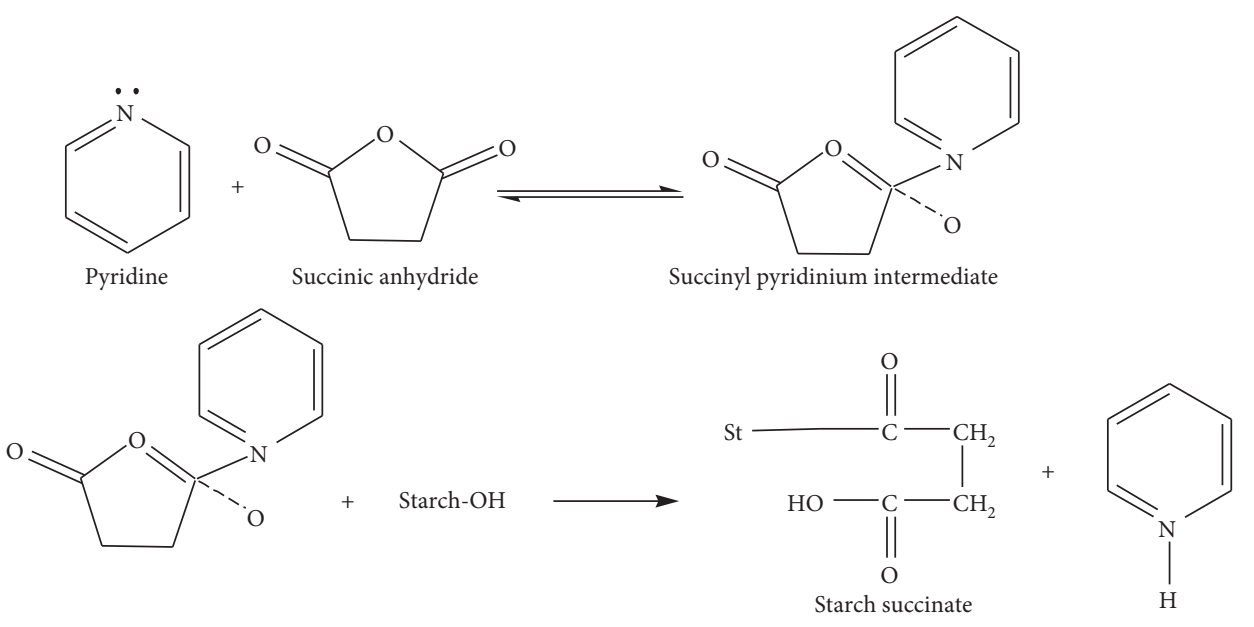

Scheme 5: Starch modification with succinate and pyridine.

internal bonding in starch granules and leads to solubilization of starch in cold water. Research has shown that succinylation reduced retrogradation in starches while the peak, cold paste and water-binding capacity, and set back viscosities improved [77]. Olayinka et al. [80] demonstarted that these parameters are increased by succinylation of red sorghum starch and decreased by modification of a white sorghum starch. The researcher stated that starch succinates have advantages such as high viscocity, greater thickening power and low gelatinization, and retrogradation [80]. Succinylated starches are used in preparation of nongelling creams due to the increase in viscosity of starch. Its improved hydrophilicity [79] makes them suitable for use as a binder in particleboards.

Hydroxypropylation is a common etherification method for starch through treatment with propylene oxide in an alkaline media [81]. Starch reacts with propylene oxide to form the hydroxylpropyl starch as shown in Scheme 6.

Hydroxypropylation decreases the ability of starch to recrystallize, which reduces the retrogradation property of starch, yielding a derivative that is stable at high temperatures [82]. Hydroxyl groups are substituted with hydroxylpropyl groups making its physicochemical properties similar to those of the carboxymethylation method. Hyroxypropyl groups disrupt inter- and intramolecular forces in starch, thus breaking hydrogen bond. This weakens the starch granules leading to its flexibility of amorphous region. Water uptake increases and thus an increase in the swellability [83]. Hydroxypropylation increases starch solubility in water and has stabilized solubility [84]. Hydroxypropylation reduces the number of hydroxyl groups in starch. This in turn reduces the hydrophilic properties of particleboards formulated with the hydropropylated starch. This will reduce water absorption and thickness selling of the particleboard.

Native starches are present in semicrystalline granular forms with certain thermal properties and functionality that have permitted its industrial use. Starch requires high heat to undergo a transition process, during which the granules break down into a mixture of polymers-in-solution, known as gelatinization. Sodium hydroxide solution reduces the temperature required by the starch to gelatinize [85].

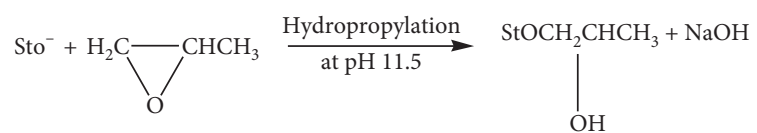

Scheme 6: Hydroxylpropylation of starch with propylene oxide.

Sodium hydroxide is meant to stabilize the viscosity of starch adhesives when they are subjected to high shearing action, heat for prolonged periods, or freeze-thaw cycles [86]. Starch reacts with sodium hydroxide to produce a cationated starch as shown in Scheme 7.

Other plasticizers apart from water and aqueous alkaline, include salt solution such as calcium chloride and potassium iodide [87]. Starch, a polyol, reacts with borax to form a borax-starch complex [88] as illustrated in Scheme 8.

Sodium hydroxide delignifies lignocellulose material by cleavage of the $\beta$-O- 4 ether bond in which sodium cation and hydroxide ion participate [89], as illustrated in Scheme 9.

Activated starch reacts with lignin in lignocellulose material to form a plasticized starch blend [90] as shown in Figure 1.

Delignification takes place during cellulosic ethanol production to form free cellulose, hemicellulose, and lignin [91]. High concentration of sodium hydroxide converts cellulose and hemicellulose into organic acids, furfural, and hydroxymethyl furfural [92]. An organic acid such as lactic acid has been used in crosslinking of starch and furfural. Furfurals were used as a substitute of formaldehyde in particleboard formulation, respectively. Lignin hydroxyl groups are oxidized to carboxylic acid in the presence of sodium hydroxide as a catalyst [93]. Carboxylic acid reacts with starch hydroxyl groups to form an ester. Ester formation is the main linkage point between the lignocellulose materials and starch binders in the proposed composite formulation for particleboard.

Citric acid and sucrose are natural adhesives [45]. Citric acid is an organic polycarboxylic acid, which contains three carboxyl groups used as cross-linking agent for wood, through esterification [94], as shown in Figure 2.

Liao et al. [45] bonded sugarcane bagasse with commercial sucrose-based adhesive modified with citric acid in the production of particleboard. The board produced had a 


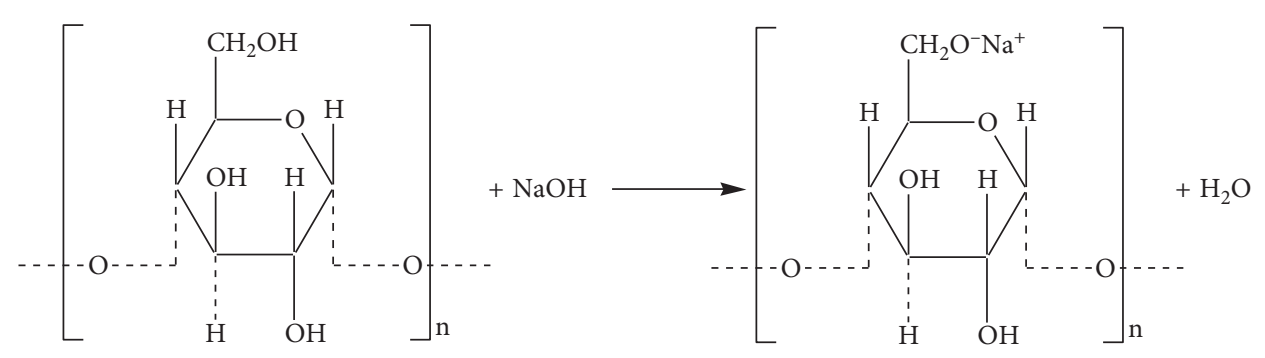

Scheme 7: Reaction between starch and sodium hydroxide.

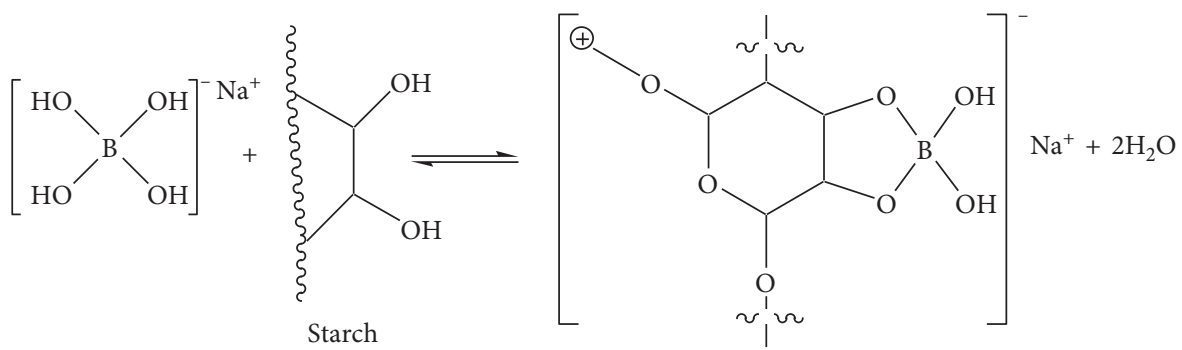

Scheme 8: Starch molecules crosslinked with borax.

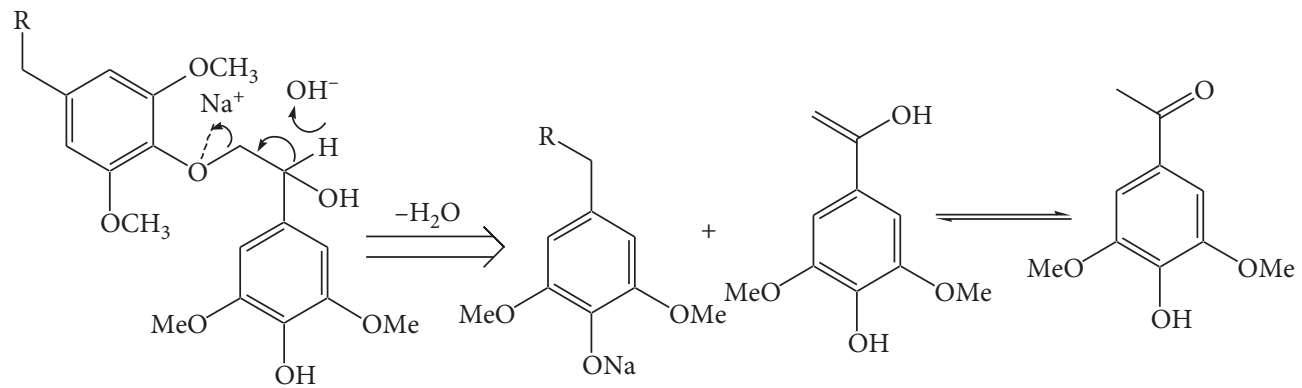

Scheme 9: Cleavage of the $\beta$-O-4 bond and formation of synringyl derivatives.<smiles>COc1cc(C(OC2C(O)C(O)OC(CO)C(O)C2O)C(CO)Oc2ccccc2OC)ccc1O</smiles>

FIGURE 1: Ether bond formed between starch and lignocellulose material.

density of $0.45 \mathrm{~g} / \mathrm{cm}^{3}$, a low density particleboard [45]. Board density between 0.35 and $0.45 \mathrm{~g} / \mathrm{cm}^{3}$ produced modulus of rapture (MOR) of $6.2 \mathrm{~N} / \mathrm{mm}^{2}$ [45]. The particleboard showed good thermal insulation properties when used as building material for thermal insulation applications. Particleboards produced had a density of $0.40 \mathrm{~g} / \mathrm{cm}^{3}$ met the requirement of Chinese national forestry industry standard. Sugarcane bagasse is rich in sugar-containing compounds that make it suitable for particleboards manufacturing [45].

Starch hydrolyzed with and acid followed with oxidation lead to the formation of aldehyde starch [95] as shown in Scheme 10. 


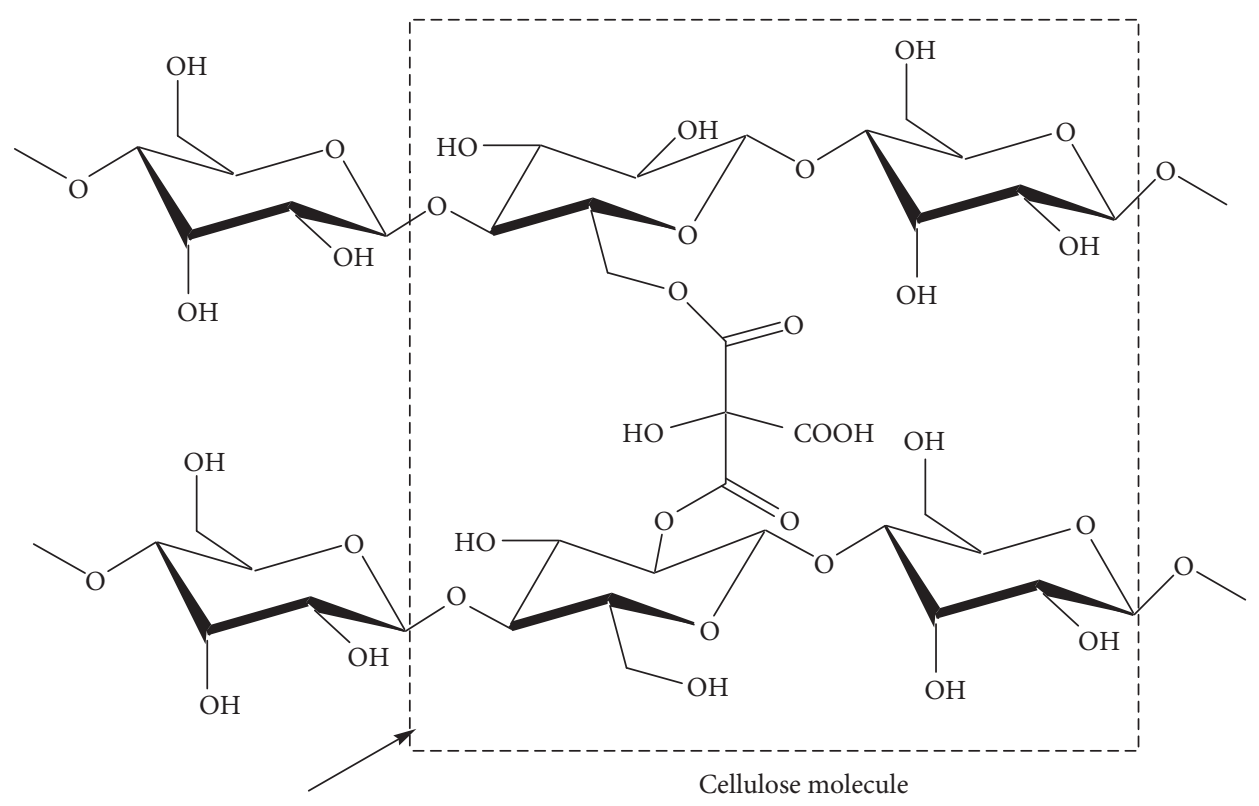

Bridging reaction

Figure 2: Reaction between citric acid and cellulose molecules [45].

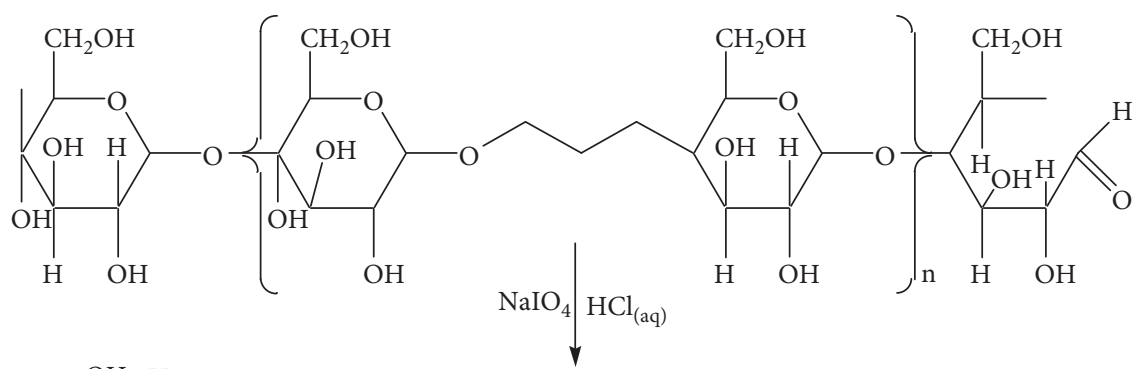

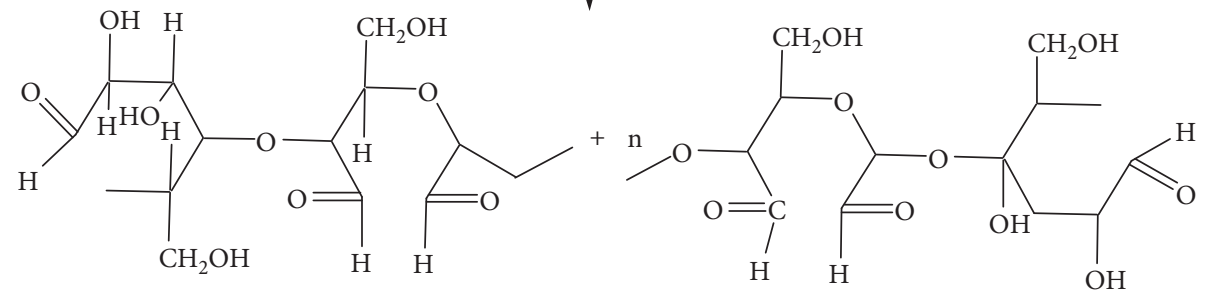

Scheme 10: Reaction of acid hydrolysis and oxidation of starch.

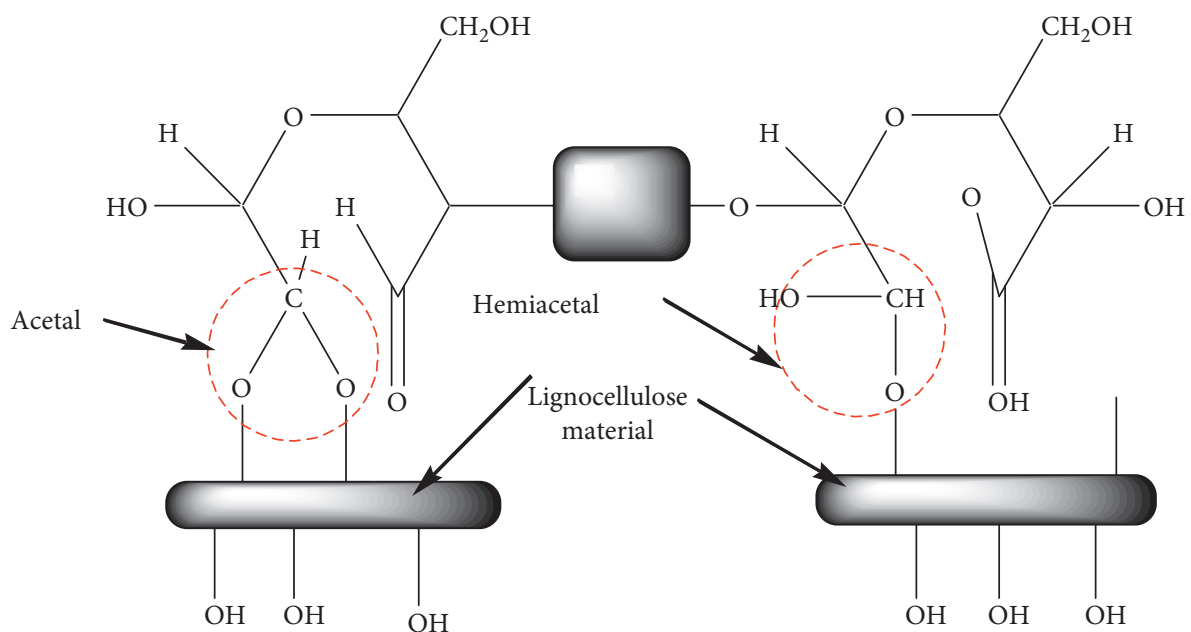

Figure 3: Acetal and hemiacetal bondage between lignocellulose material and modified starch. 
Starch dialdehyde reacts with lignocellulose material to form acetal and hemiacetal bondage $[96,97]$ as proposed in Figure 3.

\section{Conclusion}

Starch structural and functional diversity make it suitable for different applications. Various modifications will change and improve functional properties of starch and facilitate its utilization for different purposes. Starch modified with other chemicals is used as a substitute for formaldehyde-based resin in particleboard formulations. Hydroxyl group modification in starch is achieved through the introduction of alkyl groups or oxidation to carboxylic acid. This reduces the hydroxyl functional groups that determine the water absorption and thickness swelling which in turn affect the mechanical properties of particleboard. Functional groups in lignocellulose materials determine the water and thickness swelling. Interaction between modified starch-based resin and lignocellulose materials improve properties of particleboard. Mechanical strength of particleboard made from starch-based resin is due to reaction between starch and lignocellulose materials. The hydroxyl group in starch and carboxylic group in lignocellulose materials react through condensation polymerization to form ester linkages. Esterification produces hydrophobic material that reduces water absorption. Esterification also results in formation of covalent bonding that increases the interaction between components of particleboards. This in turn increases the mechanical properties of the particleboard. Unmodified hydroxyl groups in both starch and lignocellulose materials undergo etherification forming a covalent bond through ether bond. Ether and ester linkages are covalent bonds, stronger than hydrogen bonding found between the untreated starch and lignocellulose materials. Physical and mechanical properties of particleboards produced from starch-based adhesives are improved by crosslinking of the starch and lignocellulose material using borax.

\section{Disclosure}

This review is part of Ph.D. research project without any research funds.

\section{Conflicts of Interest}

The authors declare no conflicts of interest.

\section{References}

[1] T. Salthammer, S. Mentese, and R. Marutzky, "Formaldehyde in the indoor environment," Chemical Reviews, vol. 110, no. 4, pp. 2536-2572, 2010.

[2] N. S. Çetin and N. Özmen, "Use of organosolv lignin in phenol-formaldehyde resins for particleboard production," International Journal of Adhesion and Adhesives, vol. 22, no. 6 , pp. 477-480, 2002.

[3] C. A. Finch and A. Pizzi, Wood Adhesives: Chemistry and Technology, Marcel Dekkar, New York, NY, USA, 1984.

[4] M. Ghorbani, F. Liebner, H. W. G. Herwijnen et al., "Lignin phenol formaldehyde resoles: the impact of lignin type on adhesive properties," Journal for BioResource, vol. 11, pp. 6727-6741, 2016.

[5] A. Pizzi, "Recent developments in eco-efficient bio-based adhesives for wood bonding: opportunities and issues," Journal of Adhesion Science and Technology, vol. 20, no. 8, pp. 829-846, 2006.

[6] A. Pizzi and K. L. Mittal, Handbook of Adhesive Technology; Chapter 31, Marcel Dekker, New York, NY, USA, 2003.

[7] R. M. Rowell, Handbook of Wood Chemistry and Wood Composites, CRC Press, Boca Raton, FL, USA, 2013.

[8] Z. Que, T. Furuno, S. Katoh, and Y. Nishino, "Effects of ureaformaldehyde resin mole ratio on the properties of particleboard," Building and Environment, vol. 42, no. 3, pp. 1257-1263, 2007.

[9] F. C. Dupre, M. E. Foucht, W. P. Freese, K. D. Gabrielson, B. D. Gapud, and H. W. Ingram, "Cyclic urea formaldehyde prepolymer for use in phenol formaldehyde and melamine formaldehyde resin based binders," US Patent US 0,054,994, 2002.

[10] D. J. Merline, S. Vukusic, and A. A. Abdala, "Melamine formaldehyde: curing studies and reaction mechanism," Polymer Journal, vol. 45, no. 4, pp. 413-419, 2012.

[11] Y. Li, C. Ji, Y. Lu et al., "In situ synthesis of carbon $/ g-\mathrm{C}_{3} \mathrm{~N}_{4}$ composites for visible light catalysis by facile one-step pyrolysis of partially formaldehyde-modified dicyandiamide," Materials Chemistry and Physics, vol. 214, pp. 28-33, 2018.

[12] S. Boran, M. Usta, and E. Gümüşkaya, "Decreasing formaldehyde emission from medium density fiberboard panels produced by adding different amine compounds to urea formaldehyde resin," International Journal of Adhesion and Adhesives, vol. 31, no. 7, pp. 674-678, 2011.

[13] J. I. De Jong and J. de Jonge, "The reaction of urea with formaldehyde," Recueil Des Travaux Chimiques Des Pays-Bas, vol. 71, no. 7, pp. 643-660, 2010.

[14] N. A. Costa, J. Pereira, J. Ferra et al., "Scavengers for achieving zero formaldehyde emission of wood-based panels," Wood Science and Technology, vol. 47, no. 6, pp. 1261-1272, 2013.

[15] A. Marsal, S. Cuadros, A. M. Manich, F. Izquierdo, and J. Font, "Reduction of the formaldehyde content in leathers treated with formaldehyde resins by means of plant polyphenols," Journal of Cleaner Production, vol. 148, pp. 518-526, 2017.

[16] A. Takagaki, K. Fukai, F. Nanjo, Y. Hara, M. Watanabe, and S. Sakuragawa, "Application of green tea catechins as formaldehyde scavengers," Journal for the Japan Wood Research, vol. 46, p. 237, 2000.

[17] E. Bakar, E. Ulucam, and A. Cerkezkayabekir, "Protective effects of proanthocyanidin and vitamin $\mathrm{E}$ against toxic effects of formaldehyde in kidney tissue," Biotechnic \& Histochemistry, vol. 90, no. 1, pp. 69-78, 2014.

[18] Y. B. Hoong, M. T. Paridah, Y. F. Loh, M. P. Koh, C. A. Luqman, and A. Zaidon, "Acacia mangium tannin as formaldehyde scavenger for low molecular weight phenolformaldehyde resin in bonding tropical plywood," Journal of Adhesion Science and Technology, vol. 24, no. 8-10, pp. 1653-1664, 2010.

[19] B. Meyer, W. E. Johns, and J. K. Woo, "Formaldehyde release from sulfur-modified urea-formaldehyde resin systems," Journal for Forest Products, vol. 30, pp. 24-31, 1980.

[20] K.-H. Kim, S. A. Jahan, and J.-T. Lee, "Exposure to formaldehyde and its potential human health hazards," Journal of Environmental Science and Health, Part C, vol. 29, no. 4, pp. 277-299, 2011. 
[21] K. Lu, L. B. Collins, H. Ru, E. Bermudez, and J. A. Swenberg, "Distribution of DNA adducts caused by inhaled formaldehyde is consistent with induction of nasal carcinoma but not leukemia," Toxicological Sciences, vol. 116, no. 2, pp. 441-451, 2010.

[22] M. Hauptmann, P. A. Stewart, J. H. Lubin et al., "Mortality from lymphohematopoietic malignancies and brain cancer among embalmers exposed to formaldehyde," JNCI Journal of the National Cancer Institute, vol. 101, no. 24, pp. 1696-1708, 2009.

[23] R. B. Hayes, A. Blair, P. A. Stewart, R. F. Herrick, and H. Mahar, "Mortality of U.S. embalmers and funeral directors," American Journal of Industrial Medicine, vol. 18, no. 6, pp. 641-652, 1990.

[24] J. Walrath and J. F. Fraumeni, "Mortality patterns among embalmers," International Journal of Cancer, vol. 31, no. 4, pp. 407-411, 1983.

[25] J. Walrath and J. F. Fraumeni, "Cancer and other causes of death among embalmers," Journal for Cancer Research, vol. 44, no. 10, pp. 4638-4641, 1984.

[26] L. Zhang, L. E. B. Freeman, J. Nakamura et al., "Formaldehyde and leukemia: epidemiology, potential mechanisms, and implications for risk assessment," Journal for Environmental and Molecular Mutagenesis, vol. 51, pp. 181-191, 2010.

[27] L. E. Pinkerton, M. Hein, and L. Stayner, "Mortality among a cohort of garment workers exposed to formaldehyde: an update," Occupational and Environmental Medicine, vol. 61, no. 3, pp. 193-200, 2004.

[28] M. Irle, C. Belloncle, B. Guezguez, L. ., R., and R. Chauvin, "An investigation of a "green" extender for synthetic adhesives," in Proceedings of the ARBORA Conference, pp. 20-21, Bordeaux, France, November 2008.

[29] S. Kim, "The reduction of formaldehyde and VOCs emission from wood-based flooring by green adhesive using cashew nut shell liquid (CNSL)," Journal of Hazardous Materials, vol. 182, no. 1-3, pp. 919-922, 2010.

[30] Y. Liu and K. Li, "Chemical modification of soy protein for wood adhesives," Macromolecular Rapid Communications, vol. 23, no. 13, pp. 739-742, 2002

[31] K. F. Patel, H. U. Mehta, and H. C. Srivastava, "Kinetics and mechanism of oxidation of starch with sodium hypochlorite," Journal of Applied Polymer Science, vol. 18, no. 2, pp. 389-399, 1974.

[32] D. Gumul, H. Gambuś, and M. Gibiński, "Air oxidation of potato starch over zinc (II) catalyst," Journal on Carbohydrate Polymers, vol. 8, pp. 45-50, 2014.

[33] Z. Qiao, J. Gu, S. Lv, J. Cao, H. Tan, and Y. Zhang, "Preparation and properties of normal temperature cured starchbased wood adhesive," Journal on BioResources, vol. 11, pp. 4839-4849, 2016.

[34] C. Siau, A. Karim, M. Norziah, and W. Wan Rosli, "Effects of cationization on DSC thermal profiles, pasting and emulsifying properties of sago starch," Journal of the Science of Food and Agriculture, vol. 84, no. 13, pp. 1722-1730, 2004.

[35] F. Xie, L. Yu, H. Liu, and L. Chen, "Starch modification using reactive extrusion," Journal on Starch, vol. 58, pp. 131-139, 2016.

[36] Z. Huang, J. Lu, X. Li, and Z. Tong, "Effect of mechanical activation on physico-chemical properties and structure of cassava starch," Carbohydrate Polymers, vol. 68, no. 1, pp. 128-135, 2007.

[37] S. Emami, A. Perera, V. Meda, and R. T. Tyler, "Effect of microwave treatment on starch digestibility and physico- chemical properties of three barley types," Food and Bioprocess Technology, vol. 5, no. 6, pp. 2266-2274, 2012.

[38] G. Lewandowicz, T. Jankowski, and J. Fornal, "Effect of microwave radiation on physico-chemical properties and structure of cereal starches," Carbohydrate Polymers, vol. 42, no. 2, pp. 193-199, 2000.

[39] R. Czechowska-Biskup, B. Rokita, S. Lotfy, P. Ulanski, and J. M. Rosiak, "Degradation of chitosan and starch by $360-\mathrm{kHz}$ ultrasound," Journal on Carbohydrate Polymers, vol. 60, no. 2, pp. 175-184, 2013.

[40] Z. Luo, X. Fu, X. He, F. Luo, Q. Gao, and S. Yu, "Effect of ultrasonic treatment on the physicochemical properties of maize starches differing in amylose content," Journal on Starch-Stärke, vol. 60, no. 11, pp. 646-653, 2013.

[41] A. Gunaratne and R. Hoover, "Effect of heat-moisture treatment on the structure and physicochemical properties of tuber and root starches," Carbohydrate Polymers, vol. 49, no. 4, pp. 425-437, 2002.

[42] H.-J. Chung, H. S. Lim, and S.-T. Lim, "Effect of partial gelatinization and retrogradation on the enzymatic digestion of waxy rice starch," Journal of Cereal Science, vol. 43, no. 3, pp. 353-359, 2006.

[43] B. Kaur, F. Ariffin, R. Bhat, and A. A. Karim, "Progress in starch modification in the last decade," Food Hydrocolloids, vol. 26, no. 2, pp. 398-404, 2012.

[44] Y. N. Shariffa, A. A. Karim, A. Fazilah, and I. S. M. Zaidul, "Enzymatic hydrolysis of granular native and mildly heattreated tapioca and sweet potato starches at sub-gelatinization temperature," Food Hydrocolloids, vol. 23, no. 2, pp. 434-440, 2009.

[45] R. Liao, J. Xu, and K. Umemura, "Low density sugarcane bagasse particleboard bonded with citric acid and sucrose: effect of board density and additive," Journal for Bioresources, vol. 11, pp. 2174-2185, 2016.

[46] M. E. Selamat, O. Sulaiman, R. Hashim et al., "Measurement of some particleboard properties bonded with modified carboxymethyl starch of oil palm trunk," Measurement, vol. 53, pp. 251-259, 2014.

[47] J. Y. Shi and Y. Y. Tang, "Study on the rice straw-particleboard by starch-based API adhesive," Advanced Materials Research, vol. 113-116, pp. 1017-1020, 2010.

[48] I. Spiridon, C.-A. Teaca, and R. Bodirlau, "Preparation and characterization of adipic acid-modified starch microparticles/plasticized starch composite films reinforced by lignin," Journal of Materials Science, vol. 46, no. 10, pp. 3241-3251, 2010.

[49] M. Blackwell, H. Kang, A. Thomas, and P. Infante, "Formaldehyde: evidence of carcinogenicity," American Industrial Hygiene Association Journal, vol. 42, pp. 34-46, 1981.

[50] J. A. Swenberg, B. C. Moeller, and K. Lu, "Formaldehyde carcinogenicity research. 30 years and counting for mode of action, epidemiology, and cancer risk assessment," Journal on Toxicologic Pathology, vol. 41, pp. 143-148, 2013.

[51] USNTP, "National toxicology program (NTP)," Report on Carcinogens, Depart-ment of Health and Human Services, Public Health Service, National Toxicology Pro-Gram, USNTP, Patuxent River, MD, USA, 12th edition, 2011.

[52] X. Mo, E. Cheng, D. Wang, and X. S. Sun, "Physical properties of medium-density wheat straw particleboard using different adhesives," Industrial Crops and Products, vol. 18, no. 1, pp. 47-53, 2003.

[53] W. A. Mitchell, "Starch solubility," Journal of Chemical Education, vol. 54, no. 2, p. 132, 1977. 
[54] P. M. Ganorkar and A. S. Kulkarni, "Studies on preparation and functional properties of carboxymethyl starch from sorghum," Journal for Food Research, vol. 20, pp. 2205-2210, 2013.

[55] S. A. Roberts and R. E. Cameron, "The effects of concentration and sodium hydroxide on the rheological properties of potato starch gelatinisation," Carbohydrate Polymers, vol. 50, no. 2, pp. 133-143, 2002.

[56] M. Wooton and P. Ho, "Alkali gelatinisation of wheat starch," Journal for Starch-StaÈrke, vol. 41, pp. 261-265, 1989.

[57] H. Judawisastra, R. D. R. Sitohang, L. Marta, and Mardiyati, "Water absorption and its effect on the tensile properties of tapioca starch/polyvinyl alcohol bioplastics," IOP Conference Series: Materials Science and Engineering, vol. 223, Article ID 012066, 2017.

[58] S. H. Imam, L. Mao, L. Chen, and R. V. Greene, "Wood adhesive from crosslinked poly(vinyl alcohol) and partially gelatinized starch: preparation and properties," Starch-Stärke, vol. 51, no. 6, pp. 225-229, 1999.

[59] Z. Pan, A. Cathcart, and D. Wang, "Properties of particleboard bond with rice bran and polymeric methylene diphenyl diisocyanate adhesives," Industrial Crops and Products, vol. 23, no. 1, pp. 40-45, 2006.

[60] Q. Xu, J. Wen, and Z. Wang, "Preparation and properties of cassava starch-based wood adhesives," Journal on BioResources, vol. 11, pp. 6756-6767, 2016.

[61] Z. Zhu and R. Zhuo, "Controlled release of carboxylic-containing herbicides by starch-g-poly(butyl acrylate)," Journal of Applied Polymer Science, vol. 81, no. 6, pp. 1535-1543, 2001.

[62] P. Liu and Z. Su, "Surface-initiated atom transfer radical polymerization (SI-ATRP) of $n$-butyl acrylate from starch granules," Carbohydrate Polymers, vol. 62, no. 2, pp. 159-163, 2005.

[63] K. C. Gupta and S. Sahoo, "Graft copolymerization of acrylonitrile and ethyl methacrylate comonomers on cellulose using ceric ions," Biomacromolecules, vol. 2, no. 1, pp. 239247, 2001.

[64] Y.-P. Wu, Q. Qi, G.-H. Liang, and L.-Q. Zhang, “A strategy to prepare high performance starch/rubber composites: in situ modification during latex compounding process," Carbohydrate Polymers, vol. 65, no. 1, pp. 109-113, 2006.

[65] S. H. Imam, S. H. Gordon, L. Mao, and L. Chen, "Environmentally friendly wood adhesive from a renewable plant polymer: characteristics and optimization," Polymer Degradation and Stability, vol. 73, no. 3, pp. 529-533, 2001.

[66] X. Li, Z. Cai, J. E. Winandy, and A. H. Basta, "Selected properties of particleboard panels manufactured from rice straws of different geometries," Bioresource Technology, vol. 101, no. 12, pp. 4662-4666, 2010.

[67] X. Erdocia, R. Prado, M. Á. Corcuera, and J. Labidi, "Base catalyzed depolymerization of lignin: influence of organosolv lignin nature," Biomass and Bioenergy, vol. 66, pp. 379-386, 2014.

[68] A. B. Akinyemi, J. O. Afolayan, and E. O. Oluwatobi, "Some properties of composite corn cob and sawdust particle boards," Construction and Building Materials, vol. 127, pp. 436-441, 2016.

[69] J. Cui et al., "Enhancement of mechanical strength of particleboard using environmentally friendly pine (Pinus pinaster L.) tannin adhesives with cellulose nanofibers," Journal for Annals of Forest Science, vol. 72, no. 1, pp. 27-32, 2015.

[70] S. L. P. Jordan, "Inactivation of glutaraldehyde by reaction with sodium bisulfite," Journal of Toxicology And Environmental Health, vol. 47, no. 3, pp. 299-309, 1996.
[71] M. Barikani and M. Mohammadi, "Synthesis and characterization of starch-modified polyurethane," Carbohydrate Polymers, vol. 68, no. 4, pp. 773-780, 2007.

[72] F. Zia, K. M. Zia, M. Zuber, S. Kamal, and N. Aslam, "Starch based polyurethanes: a critical review updating recent literature," Carbohydrate Polymers, vol. 134, pp. 784-798, 2015.

[73] J. Fiorelli, D. D. L. Sartori, J. C. M. Cravo et al., "Sugarcane bagasse and castor oil polyurethane adhesive-based particulate composite," Materials Research, vol. 16, no. 2, pp. 439446, 2013.

[74] R. M. De Barros Filho, L. M. Mendes, K. M. Novack, L. O. Aprelini, and V. R. Botaro, "Hybrid chipboard panels based on sugarcane bagasse, urea formaldehyde and melamine formaldehyde resin," Industrial Crops and Products, vol. 33, no. 2, pp. 369-373, 2011.

[75] M. C. Sweedman, M. J. Tizzotti, C. Schäfer, and R. G. Gilbert, "Structure and physicochemical properties of octenyl succinic anhydride modified starches: a review," Carbohydrate Polymers, vol. 92, no. 1, pp. 905-920, 2013.

[76] L. Altuna, M. L. Herrera, and M. L. Foresti, "Synthesis and characterization of octenyl succinic anhydride modified starches for food applications. A review of recent literature," Food Hydrocolloids, vol. 80, pp. 97-110, 2018.

[77] Z. Sui, K. C. Huber, and J. N. BeMiller, "Effects of the order of addition of reagents and catalyst on modification of maize starches," Carbohydrate Polymers, vol. 96, no. 1, pp. 118-130, 2013.

[78] P. Bhandari and R. S. Singhal, "Studies on the optimisation of preparation of succinate derivatives from corn and amaranth starches," Carbohydrate Polymers, vol. 47, no. 3, pp. 277-283, 2002.

[79] S. Mehboob, T. M. Ali, F. Alam, and A. Hasnain, "Dual modification of native white sorghum (sorghum bicolor) starch via acid hydrolysis and succinylation," LWT-Food Science and Technology, vol. 64, no. 1, pp. 459-467, 2015.

[80] O. O. Olayinka, B. I. Olu-Owolabi, and K. O. Adebowale, "Effect of succinylation on the physicochemical, rheological, thermal and retrogradation properties of red and white sorghum starches," Food Hydrocolloids, vol. 25, no. 3, pp. 515-520, 2011.

[81] J. Singh, L. Kaur, and O. J. McCarthy, "Factors influencing the physico-chemical, morphological, thermal and rheological properties of some chemically modified starches for food applications-a review," Food Hydrocolloids, vol. 21, no. 1, pp. 1-22, 2007.

[82] J. Pal, R. S. Singhal, and P. R. Kulkarni, "Physicochemical properties of hydroxypropyl derivative from corn and amaranth starch," Carbohydrate Polymers, vol. 48, no. 1, pp. 4953, 2002.

[83] N. Masina, Y. E. Choonara, P. Kumar et al., "A review of the chemical modification techniques of starch," Carbohydrate Polymers, vol. 157, pp. 1226-1236, 2017.

[84] A. Besheer, G. Hause, J. Kressler, and K. Mäder, "Hydrophobically modified hydroxyethyl starch: synthesis, characterization, and aqueous self-assembly into nano-sized polymeric micelles and vesicles," Biomacromolecules, vol. 8, no. 2, pp. 359-367, 2007.

[85] I. D. Evans and D. R. Haisman, "The effect of solutes on the gelatinization temperature range of potato starch," Starch-Stärke, vol. 34, no. 7, pp. 224-231, 1982.

[86] A. A. Ragheb, I. Abdel-Thalouth, and S. Tawfik, "Gelatinization of starch in aqueous alkaline solutions," Starch-Stärke, vol. 47, no. 9, pp. 338-345, 1995. 
[87] J. Jane, "Starch properties, modifications, and applications," Journal of Macromolecular Science, Part A, vol. 32, no. 4, pp. 751-757, 1995.

[88] P. Erdem, E. A. Bursali, and M. Yurdakoc, "Preparation and characterization of tannic acid resin: study of boron adsorption," Environmental Progress \& Sustainable Energy, vol. 32, no. 4, pp. 1036-1044, 2012.

[89] V. M. Roberts, V. Stein, T. Reiner, A. Lemonidou, X. Li, and J. A. Lercher, "Towards quantitative catalytic lignin depolymerization," Chemistry-A European Journal, vol. 17, no. 21, pp. 5939-5948, 2011.

[90] R.-L. Wu, X.-L. Wang, F. Li, H.-Z. Li, and Y.-Z. Wang, "Green composite films prepared from cellulose, starch and lignin in room-temperature ionic liquid," Bioresource Technology, vol. 100, no. 9, pp. 2569-2574, 2009.

[91] Z. Wang, D. R. Keshwani, A. P. Redding, and J. J. Cheng, "Sodium hydroxide pretreatment and enzymatic hydrolysis of coastal Bermuda grass," Bioresource Technology, vol. 101, no. 10 , pp. $3583-3585,2010$.

[92] D. B. Hodge, M. N. Karim, D. J. Schell, and J. D. McMillan, "Soluble and insoluble solids contributions to high-solids enzymatic hydrolysis of lignocellulose," Bioresource Technology, vol. 99, no. 18, pp. 8940-8948, 2008.

[93] X. Gu, C. Kanghua, H. Ming, Y. Shi, and Z. Li, "La-modified SBA- $15 / \mathrm{H}_{2} \mathrm{O}_{2}$ systems for the microwave assisted oxidation of organosolv beech wood lignin," Maderas. Ciencia $Y$ Tecnología, vol. 14, no. 1, pp. 31-41, 2012.

[94] S. B. Vukusic, D. Katovic, C. Schramm, J. Trajkovic, and B. Sefc, "Polycarboxylic acids as non-formaldehyde antiswelling agents for wood," Holzforschung, vol. 60, no. 4, pp. 439-444, 2006

[95] Y. Zuo, W. Liu, J. Xiao, X. Zhao, Y. Zhu, and Y. Wu, "Preparation and characterization of dialdehyde starch by one-step acid hydrolysis and oxidation," International Journal of Biological Macromolecules, vol. 103, pp. 1257-1264, 2017.

[96] T. Saito and A. Isogai, "Introduction of aldehyde groups on surfaces of native cellulose fibers by TEMPO-mediated oxidation," Colloids and Surfaces A: Physicochemical and Engineering Aspects, vol. 289, no. 1-3, pp. 219-225, 2006.

[97] B. Sun, Q. Hou, Z. Liu, and Y. Ni, "Sodium periodate oxidation of cellulose nanocrystal and its application as a paper wet strength additive," Cellulose, vol. 22, no. 2, pp. 1135-1146, 2015. 

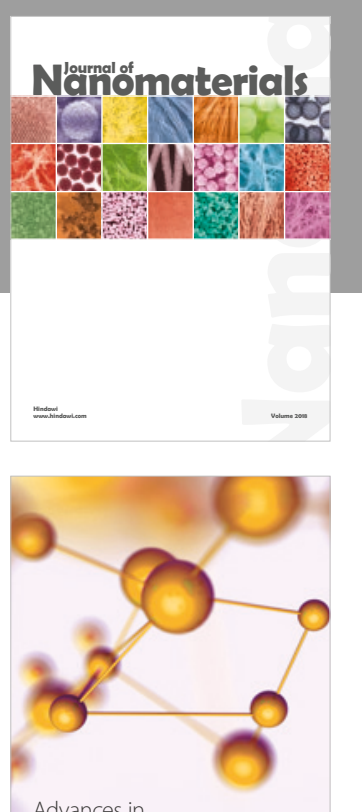

Physical Chemistry
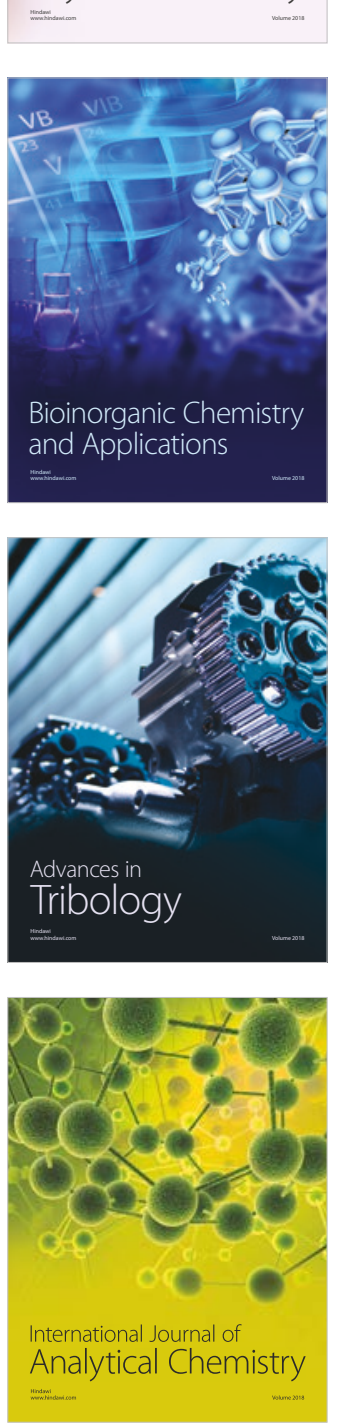

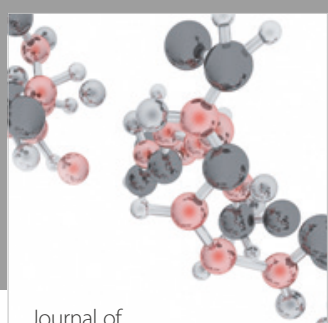

Analytical Methods

in Chemistry

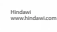

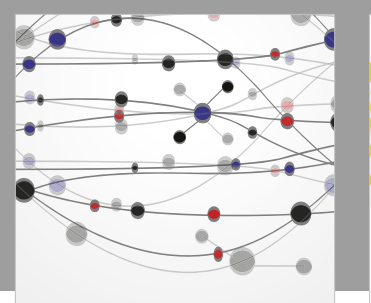

The Scientific World Journal

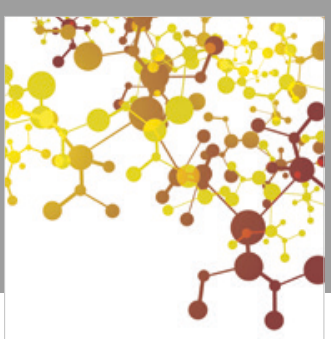

Journal of

Applied Chemistry
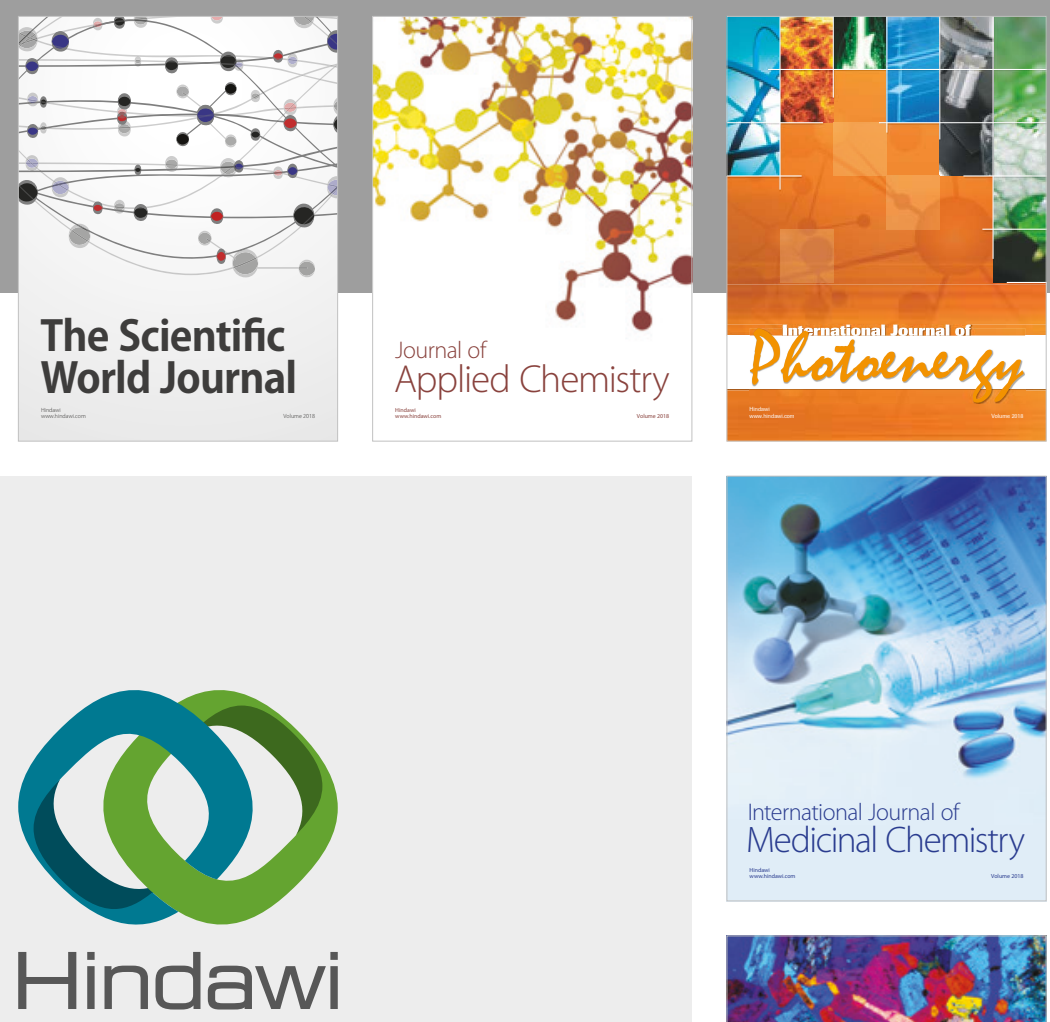

Submit your manuscripts at

www.hindawi.com
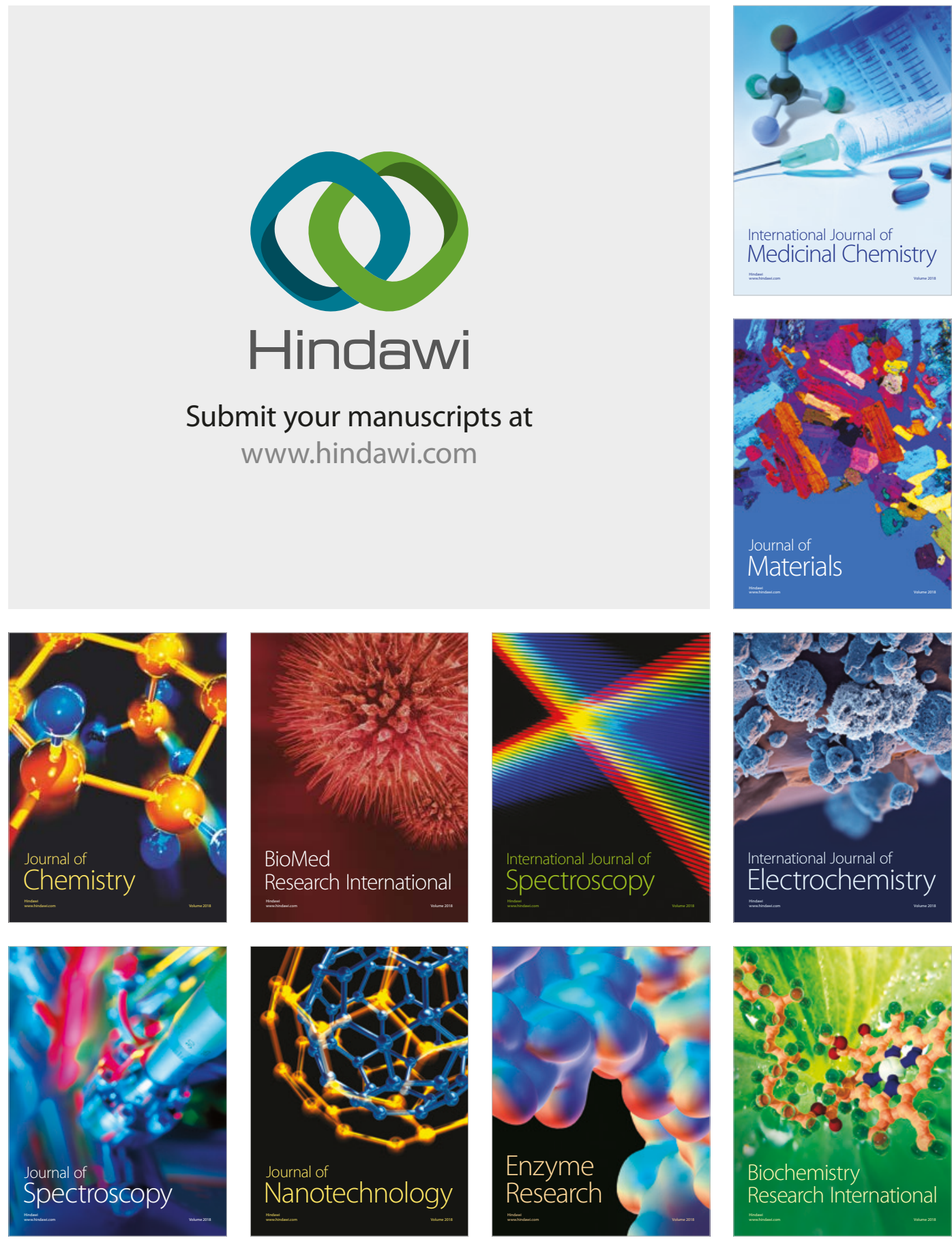
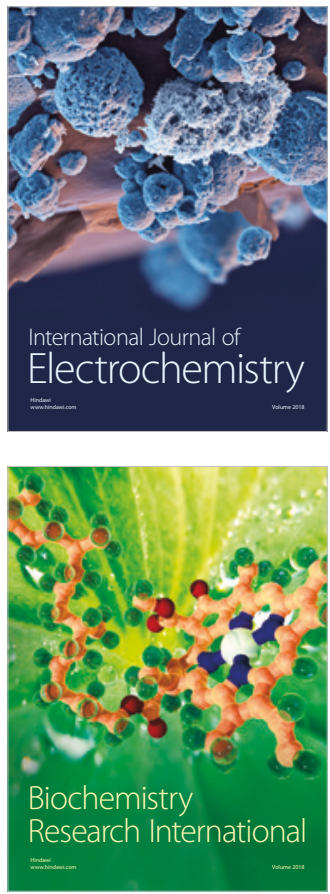